Surround control of center adaptation in the receptive fields of frog retinal ganglion

Donner, K.

Elsevier

1987

Vision Research. 1987. 27: 1211-1221

http://hdl.handle.net/1975/931

http://dx.doi.org/doi:10.1016/0042-6989(87)90196-9

Downloaded from Helda, University of Helsinki institutional repository.

This is an electronic reprint of the original article.

This reprint may differ from the original in pagination and typographic detail.

Please cite the original version. 


\title{
SURROUND CONTROL OF CENTER ADAPTATION IN THE RECEPTIVE FIELDS OF FROG RETINAL GANGLION CELLS
}

\author{
KRISTIAN DONNER \\ Department of Zoology, University of Helsinki, SF-00100 Helsinki, Finland
}

(Received 16 October 1986; in revised form 24 February 1987)

\begin{abstract}
The sensitivity and intensity-response $[R(\log I)]$ functions of the receptive field center were determined by extracellular recording from frog retinal ganglion cells. The object was to study the steady-state adapting effects of peripheral background patterns: steady annuli and spinning "windmills" of light. Steady annular backgrounds could not be shown to directly effect any change of center responsiveness, only an enhancement of late response components attributable to depression of surround sensitivity. Movement of a windmill pattern shifted $R(\log I)$ functions to higher $\log$ intensities and decreased the maximal number of spikes in the response, but did not depress the saturation level of the impulse frequency. Its action thus resembled direct light-adaptation of the center.
\end{abstract}

Retina Ganglion cell Adaptation Surround antagonism Receptive field Frog

\section{INTRODUCTION}

The control of retinal sensitivity and response properties is realized in several stages. A full functional analysis was first completed in the Necturus retina by Werblin and his colleagues (Werblin and Dowling, 1969; Werblin, 1970, 1971, 1972, 1974; Normann and Werblin, 1974; Werblin and Copenhagen, 1974; Copenhagen, 1975; Thibos and Werblin, 1978a, b) who distinguished three levels of control: the primary light-adaptation of the photoreceptors, a horizontal-cell-mediated (outer plexiform) modification of receptor-bipolar transmission (cf. Byzov and Kusnezova, 1971) associated with steady surround backgrounds, and an amacrine-cell-mediated (inner plexiform) suppression of the ganglion cell response triggered by changes in the surround pattern of illumination.

The Werblin paradigm has won wide acceptance as a framework for thinking of at least amphibian retinal function. However, there is still very limited evidence regarding the functionally central question what relative importance these different stages of control really have in shaping the output of the retina, the discharge of the ganglion cell.

In an earlier paper (Donner and Grönholm, 1984) we considered how a frog ganglion cell integrates transient signals (evoked by changes in illumination) from the receptive field (RF) surround with those from the center to form an impulse discharge. To the classical picture of center-surround organization in frog (Barlow, 1953) was added the discovery that the surround in fact consists of two distinct mechanisms: one purely suppressive (inhibitory), one responsive (but also antagonistic to the center). These might conceivably have their respective physiological basis in the inner plexiform and outer plexiform structures that are known to modify center signals in the mudpuppy (Werblin and Copenhagen, 1974; Werblin, 1974). The object of the present work is to clarify the possible importance of sustained (steady-state) surround inputs for the responsiveness of the RF center mechanism. It is to be noted that the words transient and sustained are here used only to describe the temporal properties of signals and not to designate any specific physiological mechanism.

\section{METHODS}

Impulse thresholds and discharge patterns were recorded extracellularly from the isolated eyecup of Rana temporaria. Through a twochannel optical system, where filters and masks could be independently inserted, the ganglion cells were stimulated with flashes or steps of 
light in the shape of small circular spots centred on the RF, in the presence or absence of specific background patterns. Temperature was $11-12^{\circ} \mathrm{C}$. For fuller accounts of recording and stimulation techniques, see Donner and Reuter (1968), Bäckström et al. (1978) and Donner and Grönholm (1984).

The experiments were primarily conceived on a simple stimulus-response basis, to study whether various patterns of steady-state illumination around the ganglion cell's receptive field could be shown to modify the responses to spots of light flashed on the middle of the RF. There is no necessary commitment to the idea that such effects be associated with the known RF surround mechanisms. In practice, however, it was convenient to take this as a working hypothesis when choosing suitable spatial parameters for the patterns of illumination. The assumption is then that the best selective activation of possible modulating inputs from the surround is achieved by steady-state illumination of exactly those retinal regions where the known surround mechanisms have been shown by transient stimuli to have their highest relative sensitivities (see e.g. Bäckström and Reuter, 1982; Donner and Grönholm, 1984).

\section{The center-surround organization of frog gan- glion cells}

The rationale was to selectively subject the RF center and surround(s) to appropriate steady-state patterns of "background" illumination in order to see, how this modified the properties of the center's responses to flashes and steps of light. The application of a simple center-surround paradigm to frog ganglion cells may need some justification, since these cells are often thought of as rather specialized devices for feature-detection (Lettvin et al., 1959). The fact is, however, that most cells in important respects show fairly simple center summation, surround antagonism behaviour:

(1) the responses to stimulation with spots delivered as flashes or steps of light to the RF center reveal that the primary summation of receptor signals is linear across a well-defined summation area, both at threshold and at higher intensities (Bäckström and Reuter, 1975; Donner, 1981b, 1987a);

(2) the responses to flash or step stimuli show linear summation of photons also over a certain time (some $2 \mathrm{sec}$ at the dark-adapted threshold: Donner, 1987a);

(3) the absolute sensitivity to flash or step stimuli is often very high - in many cells 5-10 photoisomerizations within the summation area and time suffice to elicit a response on half the trials (Donner, 1981b; Donner et al. 1986; Donner, 1987b), which shows that these types of stimuli cannot be considered basically inappropriate;

(4) much "feature-detecting" selectivity (such as e.g. particularly vigorous discharges to small dark spots moving in a certain direction) can be understood in terms of the general strength and spatio-temporal relations (asymmetries and delays) of the surround mechanisms, both the inhibitory (cf. Gaze and Jacobson, 1963; Grüsser et al., 1964; Grüsser and Grüsser-Cornehls, 1973; Bäckström et al., 1978) and the responsive surround (Donner and Grönholm, 1984). In the present work, concerned with steady-state effects of radially symmetric, large-field surround illumination on response parameters chosen to reflect pure center responsiveness (see below), such asymmetries are unimportant. What is important is that the surround mechanisms have large portions of their spatial sensitivity distributions outside that of the center mechanism.

It is true that there are frog ganglion cells which respond only reluctantly to e.g. stationary spots of light (especially at medium intensities, cf. Donner, 1981a), but such cells were not used here.

The cells chosen all represent the classes 1,2 or 3 of Maturana et al. (1960); the criteria for classification were as described by Donner and Grönholm (1984). These cells respond with a spiking discharge to a spot of light on the RF center both when it is turned on and when it is turned off, but they have practically no maintained discharge.

\section{Stimulation}

Both background and stimulus patterns were produced by inserting masks into the respective light channel. The backgrounds used were of four types: (1) full-field (ca $3 \mathrm{~mm}$ dia) or largefield $(1.9 \mathrm{~mm}$ dia $)$ covering a great part of the retina, or at least extending far beyond the RF center; (2) local backgrounds not exceeding the size of the RF center of the cell under study. The purpose was to light-adapt the central receptors while causing as little surround activity as possible. The stimulus spot was then chosen to be only slightly smaller than the background spot and superposed on the latter. Care was taken that the spots were positioned in perfect register 
(see below); (3) steady annular backgrounds. These were selected to have strong influence on the surround while illuminating the central receptors as little as possible; therefore the inner diameter of the annulus always exceeded the diameter of the RF center. The problem of the optimal annulus is treated in detail by Donner and Grönholm (1984); (4) windmill patterns on the RF surround, standing or spinning. As this work was not concerned with a quantitative assessment of the effects of varying windmill parameters, only a few patterns were tried. In view of results of Bäckström and Reuter (1982) showing the zone of maximum inhibitory effectiveness to lie some $0.5 \mathrm{~mm}$ from the RF midpoint, the windmills were chosen to cover an annular region of inner diameter $0.57 \mathrm{~mm}$ and outer diameter $1.1 \mathrm{~mm}$ - this was expected to give good inhibition without significantly encroaching on the RF center of any cell. Of this annular area, the windmills always illuminated a total of $145^{\circ}$ or $40 \%$ symmetrically distributed on either ten, four or two sails. The mask was concentrically mounted on the end of a rigid tube held on ball bearings by a manipulator and driven at $11 \mathrm{rpm}$ by a synchronic motor (Stirling).

The backgrounds were always turned on at least $10 \mathrm{~min}$ before the recording of center responses started, so that a true steady-state prevailed.

At a point before the joint background and stimulus beams entered the otherwise light-tight box containing the eye, part of the light was deflected to form an image on the wall. When a cell was found, its receptive field was localized in both channels independently; the agreement on the wall projection was always excellent. Before and after each experiment it was checked that the stimulus and background images were in register on the retina as well and that focussing was satisfactory (visual inspection through a preparation microscope). Optically unsatisfactory experiments were discarded.

In the case of annular-type backgrounds it should be noted that the contrast attainable between the illumination in the periphery and the middle is limited by stray light. Scatter from the surround backgrounds used here on to the centre was about $6 \%$ (for a detailed account, see Donner and Grönholm, 1984), so the ratio center was about $6 \%$ (for a detailed account, see Donner and Grönholm, 1984), so the ratio were reached where this scattered background light already adapted the RF center up into the
Weber range, an increase in annular intensity no longer changed the physiological contrast between periphery and middle, it only implied a general transition to more light-adapted states.

\section{Measures of the RF center's responsiveness}

Only on-type responses (i.e. responses to onsteps or flashes of light) were considered. When the object is to detect and quantify possible modifications in the transmission of receptor signals by the center mechanism, it is obviously important to know as accurately as possible the shape of the relevant aspect of the receptor event. Whereas the rising (hyperpolarization) phase of photoreceptor responses is well characterized, with a basically linear dependence on stimulus intensity, the shape of the decay (depolarization) phase, which determines off-responses, is much more difficult to know with confidence, i.e. because of its nonmonotone intensity-dependence (Baylor et al. 1974; Baylor et al. 1979; Donner and Hemilä, 1985; cf. also Pickering and Varju, 1967; Newman and Lettvin, 1978).

Sensitivity was measured as the reciprocal of the threshold intensity for a spiking response. That intensity was determined by stimulating the cell a great number of times at $0.1 \log$ unit intensity intervals around threshold and finding the lowest intensity which elicited at least one spike on at least half of the trials.

Intensity-response functions [here, $R=R(\log$ I) functions] can be constructed on the basis of any response parameter one may wish. The conclusions may largely depend on which aspect of the responses one chooses to consider. The present work focusses on three parameters: response latency, initial impulse frequency and total number of spikes.

Latency taken from stimulus onset to the first spike is a good measure of the degree of excitation of the excitatory center mechanism, prior to inhibition, displaying threshold-like linear spatial summation over a very wide range of stimulus intensities (cf. Donner, 1981b). This parameter is most conveniently handled in the form of reciprocal latencies ("response speed"), whereby the dependence on log stimulus intensity becomes linear [see Fig. 1(A)].

Biologically more relevant is the initial impulse frequency, here measured over the first four spikes. This pre-inhibitory burst parallels reciprocal latency being near-linear in $\log I$ and showing threshold-like summation over a certain range of stimulus intensities, but it saturates 
much earlier (see Donner, 1981a, b). At high stimulus intensities the responses to spots of light usually consist of only a brief burst, which thus must convey all the brightness information. As a tool, initial frequency is useful because in most cases it reflects the excitatory process undistorted by stimulus-activated antagonism (Donner, 1981a).

The total number of spikes is here used to characterize the full spiking discharge, which at low stimulus intensities may be much longer than the initial burst. This response measure certainly conveys biologically important information, but it is difficult to interpret from the viewpoint of mechanism, because it reflects the final outcome of central excitation and stimulusactivated surround antagonsim. Only very early response components can generally be used as measures of center activity (Donner, $1981 \mathrm{a}, \mathrm{b}$; Donner and Grönholm, 1984; cf. also EnrothCugell et al. 1975).

\section{RESULTS}

General light-adaptation by large-field backgrounds

This section shortly reviews how the center's responsiveness is changed by homogeneous light-adaptation. The purpose is to obtain a base for comparison with changes due to more specific background configurations.

Sensitivity. The effects of a general background on increment thresholds are well known and will not be demonstrated here (see e.g. Barlow, 1965; Barlow and Levick, 1976; Donner, 1981a; Reuter et al., 1986; see also Fig. 3). After a low-intensity range of background intensities not affecting thresholds comes a range where the threshold intensity increment approximately follows the square root of background intensity. This finally gives way to a range of steeper threshold-background-dependence where the exact slope depeends on the stimulus used, but is often close to 1 (Weber's law). These general characteristics should be borne in mind when the effects of more specific background patterns are judged (Figs 3 and 5).

Intensity-response functions. Figure 1 shows the effects of rising background intensities on the $R(\log I)$-functions of reciprocal latency (A) and initial impulse frequency (B). There are three conclusions to be drawn from the figure: (1) both $R(\log I)$-functions are shifted towards higher $\log I$ values; (2) the slopes of their linear portions get steeper (so the range of graded
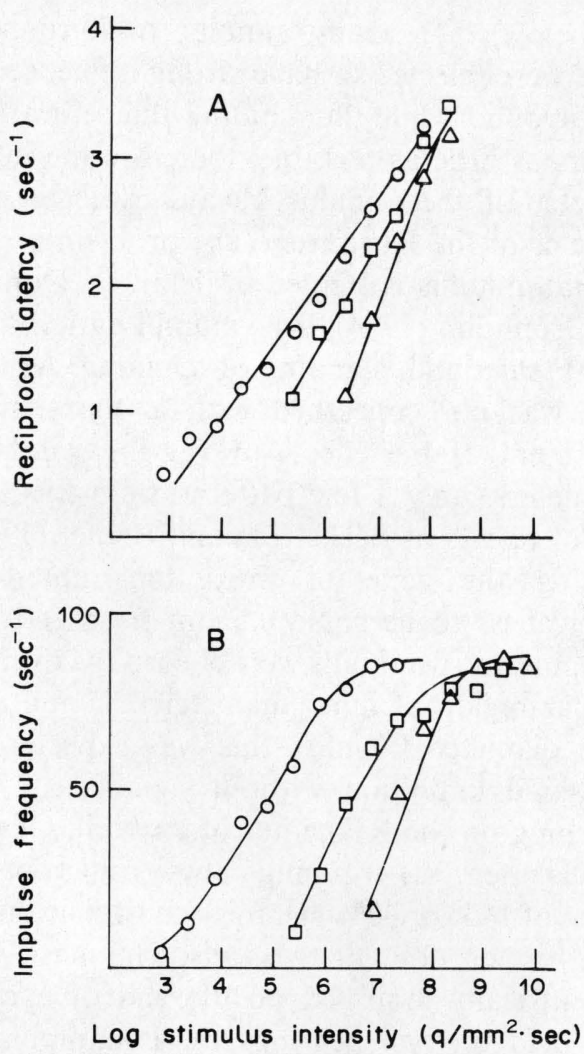

Fig. 1. How light-adaptation by large-field backgrounds changes the intensity-response functions reflecting early response components. (A) reciprocal response latency, (B) initial impulse frequency. All the curves were recorded in the presence of full-field $615 \mathrm{~nm}$ backgrounds of log intensities 4.2 (circles), 7.7 (squares) and 8.3 (triangles) incident quanta $/ \mathrm{mm}^{2}$ s. The two latter backgrounds elevated thresholds by 2.4 and $3.5 \mathrm{log}$ units compared with the weakest one. The stimulus was a $513 \mathrm{~nm}$ spot of $0.3 \mathrm{~mm}$ dia given as an on-step.

impulse frequencies gets narrower); (3) in the frequency curves, the maximum remains unaltered. The existence of a saturation level is, within the range of intensities used here, a characteristic of frequency alone, but otherwise reciprocal latency and initial impulse frequency behave much in concert.

By contrast, Fig. 2 shows how the number of spikes in the response (again as a function of $\log I$ ) changes with light-adaptation. As pointed out in the Methods section, this response measure is determined by the interplay of the excitatory and inhibitory signals evoked by the stimulus and is therefore less well suited for studying how center excitation as such is modified by background lights. When light-adapted, these $R(\log I)$-functions are not only shifted to the right, but also compressed. Moreover, the degree of compression depends on the size of 


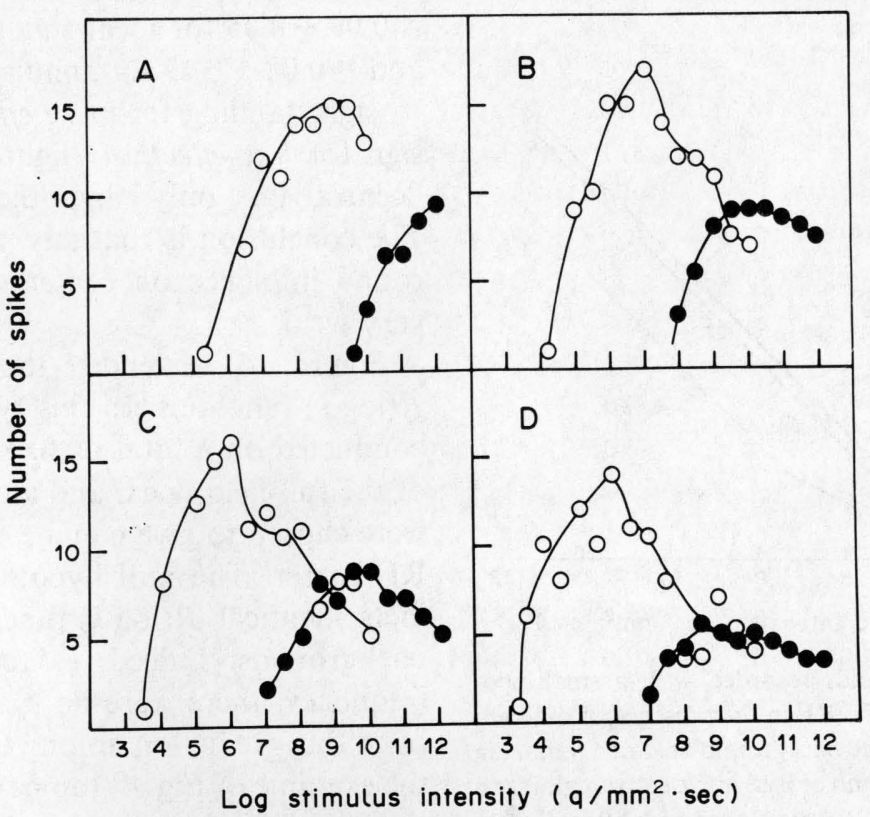

Fig. 2. How light-adaptation changes the number of spikes in the response to different-sized test spots, expressed as a function of the log intensity of the spot. Spot sizes were: (A) $0.027 \mathrm{~mm}$, (B) $0.11 \mathrm{~mm}$, (C) $0.3 \mathrm{~mm}$ and (D) $0.8 \mathrm{~mm}$ dia. The diameter of the RF center was about $0.4 \mathrm{~mm}$ as determined by the area-threshold method. Open circles refer to the dark-adapted situation, solid circles to responses obtained in the presence of a large-field $558 \mathrm{~nm}$ background of $\log$ intensity 7 incident quanta/mm $\mathrm{mm}^{2}$. (Average threshold rise $3.5 \log$ units.)

the test spot used: for instance, the response maximum for the largest spot in Fig. 2 (D) has been compressed by $60 \%$, that for the smallest spot (A) by less than $40 \%$, while (B) and $(C)$ are intermediate. Functionally this can be seen as a certain effectivization of spatial high-pass filtering.

\section{Steady surround backgrounds}

Above it was shown that light-adaptation shifts $R(\log I)$-functions rightwards. Amphibian photoreceptors are known to light-adapt in this manner (cf. Hemilä, 1977; Bäckström and Hemilä, 1979). On the other hand, Werblin's (1974) analysis suggests that a shift can take place because of lateral (horizontal-cell) action on receptor-bipolar transmission, aligning the steepest part of that function with the mean level of illumination. The purpose of the experiments reported in this section was to investigate whether the threshold-setting and the shifts of the $R(\log I)$-curves under steady backgrounds can be wholly explained by the adaptation of the central photoreceptors or whether an additional sustained surround control is important.

The rightward shift is most easily measured as a threshold rise. Therefore, increment thresholds were recorded against increasing intensities of three different background configurations: (1) a small spot roughly matching the RF center and itself just containing the test spot; (2) an annulus of inner dia just above that of the RF center and $1.9 \mathrm{~mm}$ outer dia; (3) a large spot of $1.9 \mathrm{~mm}$ dia. The null hypothesis - no surround control-would imply that the adapting effect of each background is determined solely by the light flux it throws on the RF center. If there is an important surround contribution to the sensitivity-setting at the ganglion cell level, background (2), misaligning the operating ranges of central receptors and bipolars, should be more desensitizing than expected from its light scatter. At higher intensities, background (1) should be more desensitizing than (3), because of the absence of a desaturating surround input.

These predictions were not borne out by the experiments, as shown by the example in Fig. 3 . A standard increment-threshold curve consisting of zero-effect, square root and Weber ranges (slopes $0,0.5$ and 1 in the $\log$-log plot) has been fitted by eye to the data for the largefield background (squares). This curve has then been shifted to the right in proportion to the relatively smaller total light fluxes that the two other backgrounds are estimated to throw on 


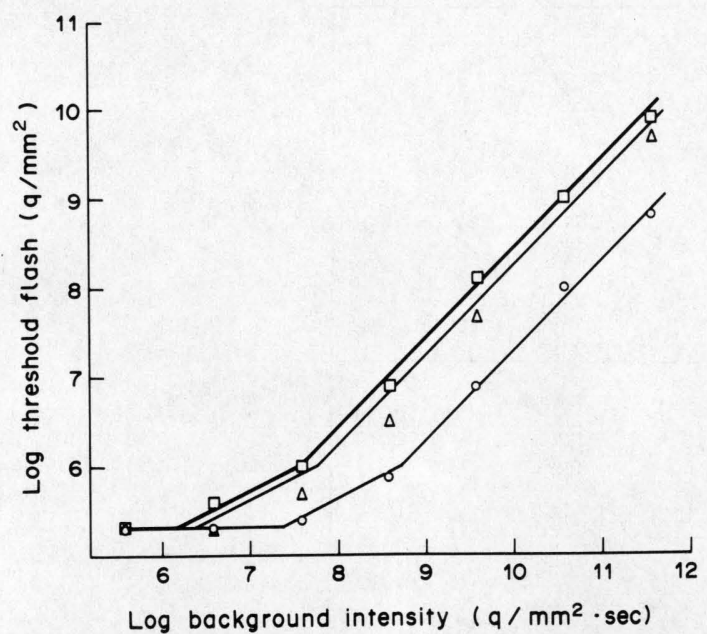

Fig. 3. Increment thresholds recorded with a small spot flashed on the middle of the RF in the presence of different steady backgrounds: a large background field of $1.9 \mathrm{~mm}$ dia (squares), a local background of $0.18 \mathrm{~mm}$ dia (triangles) and an annular background of $0.3 \mathrm{~mm}$ inner and $1.9 \mathrm{~mm}$ outer dia (circles), all concentric with the RF. The bold line is an increment threshold function consisting of three straight segments with slopes 0, 0.5 and 1 (cf. Barlow, 1965; Reuter et al., 1986) fitted by eye to the data points for the large-field background. The thin lines are the same function shifted to the right according to the estimated log differences of the three backgrounds as regards photon flux thrown on the $R F$ center. This was estimated as follows: by area-threshold measurements the diameter of the RF center was determined to $0.23 \mathrm{~mm}$. The large-field background covers this fully, giving relative flux 1.0 on the RF center. The small-spot background covers a fraction $0.18^{2} / 0.23^{2}=0.6$ of the center, casting precisely that fraction of the flux of an equalintensity large field. The shift is then $\log (0.6)=-0.2 \log$ units. The annulus scatters $6 \%$ of its nominal intensity on the center (see Methods), requiring a shift $=\log (0.06)=$ $-1.2 \log$ units. $513 \mathrm{~nm}$ stimulus (17 msec, $0.17 \mathrm{~mm} \mathrm{dia)}$; $558 \mathrm{~nm}$ backgrounds.

the center (see caption to Fig. 3). This implies that, to the extent that the curves fit the points, sensitivity is determined by central flux alone. The fit is seen to be good for the annular background. The local small-spot background is somewhat less adapting than expected, possibly because of a slight inaccuracy in the determination of center size (and thus of the fraction of the RF center covered by this background). Although small deviations occurred in other experiments as well, in the eight cells studied there was no significant trend for any of the backgrounds to be less or more effective than expected from the flux it threw on the RF center. A deviation from the null hypothesis may be defined $d=\log \left(I_{\mathrm{t}} / I_{t 0}\right)$, where $I_{\mathrm{t}}$ is the observed threshold intensity and $I_{\mathrm{t} 0}$ is that predicted by the hypothesis. Mean $d$ was then
$-0.09 \pm 0.05$ for local small-spot backgrounds and $+0.08 \pm 0.17$ for annular backgrounds, the + sign standing for more effectively and the sign for less effectively light-adapting than the "central flux only" hypothesis would predict. The conclusion is that any possible steady surround influence on center sensitivity must be very weak.

Figure 4 extends the study to full $R(\log I)$-functions. In this type of experiments, conducted on a total of six cells, the intensities of the full-field, local and annular backgrounds were chosen to give equal estimated flux on the RF center. The null hypothesis therefore predicts identical $R(\log I)$-functions for all three backgrounds. Indeed, as regards latency and frequency, there were no systematic deviations from this prediction among the cells studied. In the example of Fig. 4 (top panels), it can be seen that the differences in these parameters appear insignificant, certainly not involving any extra rightward shift or frequency compression due to the surround background.

Facilitation. The bottom panel of Fig. 4, however, shows that in terms of the total number of spikes there is a significant response enhancement by steady backgrounds extending into the periphery as compared with the local background confined to the middle of the RF. Several earlier workers have documented some form of "sensitization" of the center response of amphibian ganglion cells due to steady surround illumination (Burkhardt and Berndtson, 1972; Burkhardt, 1974; Copenhagen, 1975; Mooney, 1979; Bäckström and Reuter, 1982). It is seen in situations where a local background is enlarged beyond the RF center (or when e.g. an annulus is added around a central background). Thus it resembles the bipolar cell sensitization interpreted as a desaturation due to horizontal cell input (Burkhardt, 1974; Werblin, 1974).

A type of facilitation really boosting the primary excitatory signal should, however, have shown up both in the threshold experiments (cf. Fig. 3) and in the early response parameters (top panels in Fig. 4), but, as seen above, little or no such effects could be detected. Note particularly that the late response component (evidenced by the total spike number) was enhanced by the extension of the background especially in the high-intensity range, where there were no differences in initial impulse frequencies. A possible description is that there is a change in the bandpass characteristics of the excitatory center pathway. However, there is 


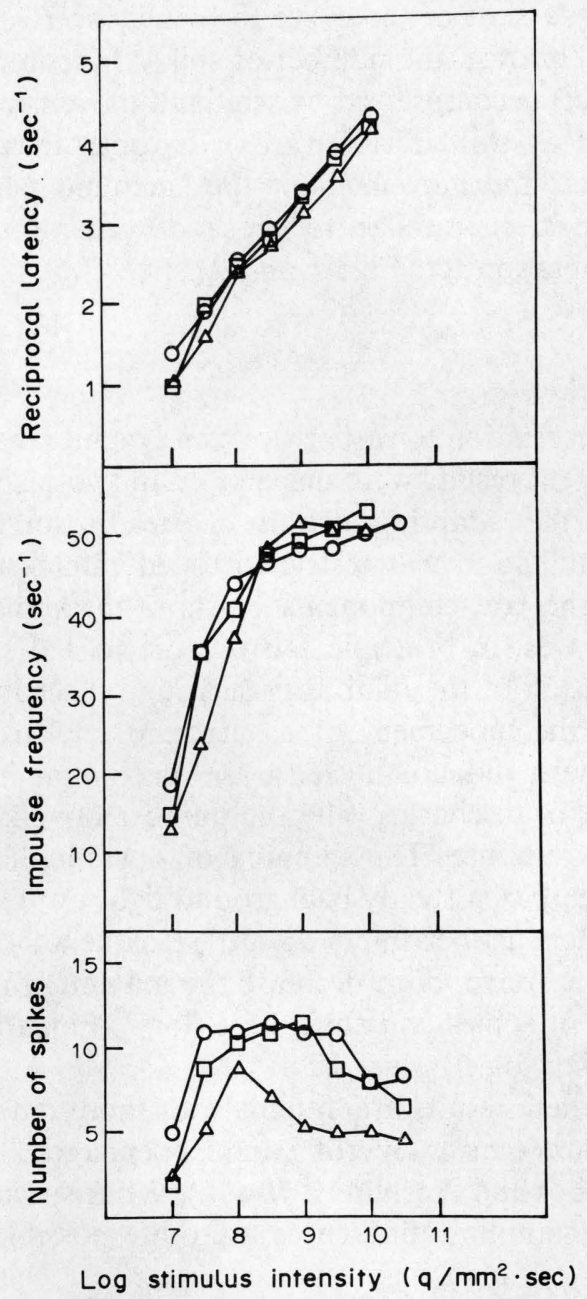

Fig. 4. Intensity-response functions recorded with a small test spot on the middle of the RF in the presence of a concentric local background (triangles; small-spot, $0.18 \mathrm{~mm}$ dia), annular background (circles; inner dia 0.18 , outer $0.67 \mathrm{~mm}$ ) and full-field background (squares). Top panel: reciprocal latencies, middle: initial discharge rate, bottom: total number of spikes in the response. The center diameter was about $0.18 \mathrm{~mm}$ as determined by area-threshold recording. The background intensities were set to give equal threshold rises, arguably corresponding to equal flux on the RF center: full-field 7.3, small-spot 7.3 and annular 8.2 $\log$ units (quanta $/ \mathrm{mm}^{2} \mathrm{~s}, 558 \mathrm{~nm}$ ). Calculating with $6 \%$ scatter (see Methods), the intensity of the annular background ought to have been 8.5 ; since thresholds may fluctuate somewhat during an experiment, it is possible that the threshold-determined value 8.2 was slightly too low$513 \mathrm{~nm}$ on-step stimulus $(0.17 \mathrm{~mm} \mathrm{dia})$.

a more straightforward explanation involving the relative weighting of central excitatory and lateral inhibitory inputs. A central small-spot background heavily depresses the sensitivity of the center, affecting the surround mechanism much less. Extending the background then mainly acts to light-adapt the surround, shifting the balance in favour of the center (cf. EnrothCugell et al., 1975). This would lead, i.a., to an increased delay of the stimulus-activated inhibition relative to the excitation, hence to a longer and stronger discharge (Donner, 1981b).

\section{Moving surround backgrounds}

In these experiments the effects of a Werblintype windmill rotating over the RF surround were studied. The object was to see whether a sustained input from a change-sensitive surround could be achieved and how it would modify center responsiveness.

Pilot experiments showed that all the windmills described in the Methods section were able to elevate center thresholds, but the one with only two sails was most effective. So the results described below were all obtained with that windmill; the ones with finer divisions acted similarly but more weakly.

Figure 5 illustrates how the response threshold of the RF center rose as a consequence of the spinning of the surround windmill at different intensities of the windmill. The figure compares thresholds in the presence of the same windmill, which is either standing (open circles) or spinning (solid circles). Note that due to stray light the RF center is gradually light-adapted as windmill intensity is raised, but since the fraction of light scattered stays constant, the intensity contrast stays constant throughout. So

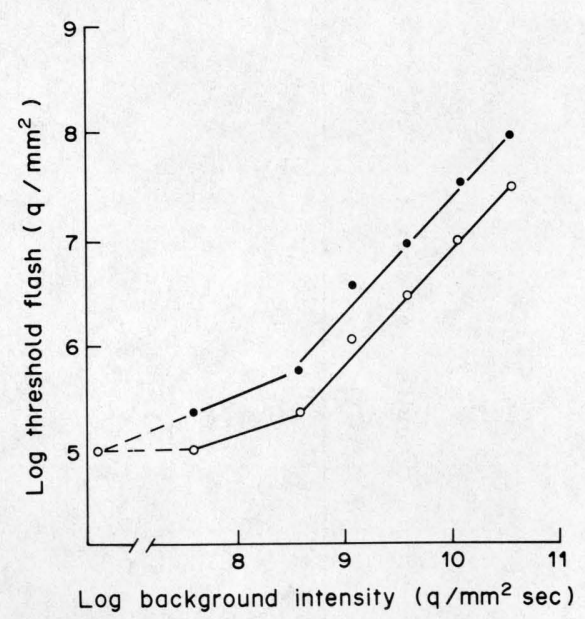

Fig. 5. Threshold elevation due to the rotation of a windmill background on the RF periphery. The points give response thresholds to a small test spot $(513 \mathrm{~nm}, 0.18 \mathrm{~mm}$ dia $)$ flashed $(17 \mathrm{msec})$ on the middle of the RF in the presence of a windmill which was either stopped (open circles) or spinning (solid circles). The abscissa gives the intensity of the windmill (wavelength $558 \mathrm{~nm}$ ). 
Fig. 5 essentially shows what the spinning of a constant-contrast windmill does to ganglion cell sensitivity in different states of lightadaptation. It is evident that, from a certain intensity upwards, the antagonism evoked by the movement of the windmill is remarkably constant, amounting to an apparent attenuation of the stimulus light by in this case roughly $0.5 \log$ units. In the three other cells where this type of experiment was performed the effect was entirely similar, with only quantitative differences between cells (apparent attenuation 0.3, 0.8 and $0.9 \log$ units).

In the mudpuppy, the effect of a moving windmill background has been described as a compression of the $R(\log I)$-function (Werblin and Copenhagen, 1974; Thibos and Werblin, 1978b). In order to clarify whether this is true of frog ganglion cells, full stimulus-response functions were recorded in the presence of both standing and spinning windmills. In Fig. 6 the two response parameters for which a maximum level can be studied, initial frequency and number of spikes, have been plotted from one such experiment: open circles give values obtained while a standing windmill was shone on the surround, filled circles values obtained while the windmill was spinning, and triangles controls without windmills. It is seen that the spinning of the windmill caused no frequency compression, only a shift of the curve to higher $\log I$ values. By contrast, the number of spikes function (the Inset) is compressed by windmill movement (as well as shifted rightwards). In both these respects the movement of the surround pattern has effects similar to those of general lightadaptation (cf. Figs 1 and 2).

\section{DISCUSSION}

In relation to earlier work on amphibians, the present results were unexpected in two respects: (1) the adapting action of steady surround illumination was restricted to an enhancement of the late components of supra-threshold responses, in principle attributable to a desensitization of the inhibitory surround mechanism; (2) the movement of a surround background pattern did not decrease the maximum initial rate of discharge, only the number of spikes in the response. The spinning of a windmill thus resembles a steady background light on the RF center: neither limits the cell's frequency range from above, both decrease the maximum number of spikes and shift the $R(\log I)$-function to higher $\log I$ ranges.

These results are at odds with those reported from Necturus (Werblin and Copenhagen, 1974; Thibos and Werblin, $1978 \mathrm{a}, \mathrm{b}$ ). While species or cell sampling differences are quite possible ex-

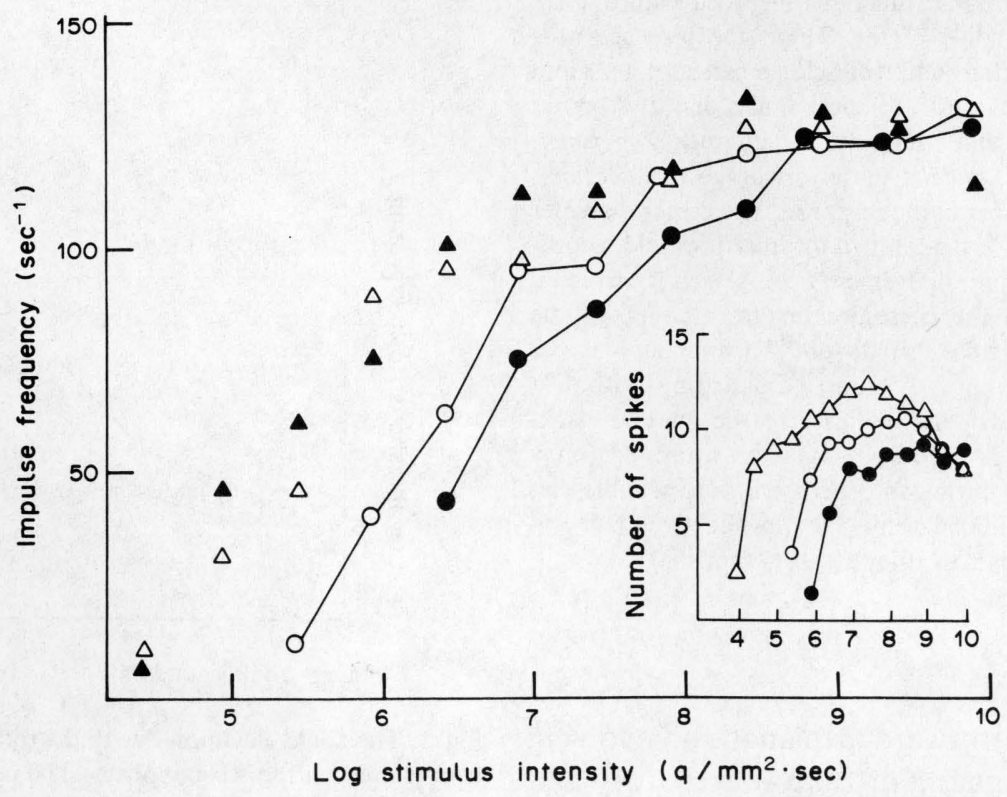

Fig. 6. The initial impulse frequency and (Inset) the total number of spikes of responses recorded in the presence of a windmill background which was either stopped (open circles) or spinning (solid circles), and in the absence of it (triangles: open-before; solid - after windmill recordings). Central $513 \mathrm{~nm}$ test spot ( $0.3 \mathrm{~mm}$ dia) delivered as on-step. Windmill $\log$ intensity was 8.6 (quanta ${ }_{558} / \mathrm{mm}^{2} \mathrm{~s}$ ). 
planations, there are some other points which merit attention.

\section{Steady surround illumination and center responsiveness}

The evidence of Thibos and Werblin (1978a) for the shifting of ganglion cell operating curves by steady surround backgrounds is, in fact, problematic. They did not evaluate light scatter, and their arguments against light scattered on to the center being responsible are not compelling: (a) the lack of center responses when the surround background was turned on and off could well have been due to the simultaneous activation of transient, both antagonistic and downright inhibitory, influences from the surround (see Donner and Grönholm, 1984); (b) the fact that the surround caused the bipolar membrane to polarize in a direction opposite to that of a center response only implies that the transient surround input outweighed the transient center excitation from scattered light. At any rate it is quite evident that over the whole $6 \log$ unit range of annular intensities used, the light scattered onto the center cannot have remained negligible.

The main point to be noted, however, when judging a possible discrepancy is that Thibos and Werblin (1978a) did not shine the surround background continuously, but turned it on $3 \mathrm{sec}$ before each presentation of the stimulus. Thus they may have measured a transient effect of the responsive surround (cf. Donner and Grönholm, 1984).

Also, their reference to Enroth-Cugell and Lennie (1975) regarding an alleged shift of cat ganglion cell operating curves due to steady backgrounds is erroneous: the latter authors flashed the annulus together with the central stimulus, thereby evoking a change-dependent type of surround antagonism. On the contrary, Enroth-Cugell et al. (1975) found no effect on center sensitivity from steady illumination of the surround. In agreement with the present study they concluded that, in the cat, a steady surround background acts only by desensitizing (light-adapting) the surround mechanism. Particularly in work dealing with facilitation effects in the retina, too little attention has usually been paid to this obvious possiblity: that "sensitization" may in fact be due to the desensitization of an inhibitory mechanism (e.g. Copenhagen, 1975; Marchiafava, 1983).

From a functional point of view, one might argue that the question whether there is a truly sustained surround antagonism is uninteresting, because for real vision, involving perpetually shifting retinal images, it is simply not needed. Still, it is important to bear in mind that even a slowly decaying antagonism, as (arguably) studied by Thibos and Werblin (1978a), does not set a steady state of adaptation comparable to the adaptation of the photoreceptors themselves. Indeed, in human psychophysics the sensitization achieved when a local adapting spot is extended beyond the summation area (Westheimer, 1965) has been seen only with images that are either unstabilized or stabilized for, at the most, a fraction of a minute (Teller et al. 1966; Barlow, 1972). The present results may therefore explain why Westheimer (1968) found no sensitization from annuli of "dark light" induced by local bleaches - these would be like completely stabilized background images, exerting no effect on center thresholds.

\section{Movement in the surround}

The second apparent difference as compared with Necturus results, the lack of compression of the impulse frequency-log $I$ function, may well have to do with the choice of response parameters. It seems likely that the initial impulse frequency of frog supra-threshold responses is determined by the steepness of the rising excitatory signal (Donner, in preparation), not by its peak amplitude, which was the parameter considered by Werblin and Copenhagen (1974). Nor is it strictly comparable to the spike frequency of a $1 \mathrm{sec}$ interval as used by Thibos and Werblin (1978b). At high stimulus intensities, the first four spikes occupy only some $40 \mathrm{msec}$ even at the low temperature $\left(\mathrm{ca} 11.5^{\circ} \mathrm{C}\right)$ of the present experiments. The "slow" measures of Werblin and his co-workers are probably more closely related to the total number of spikes as used here-this response measure really was compressed, but, as discussed above, it cannot as such be taken to reflect a property of the center pathway. Enroth-Cugell and Jakiela (1980), in the cat, also found that the initial peak of the ganglion cell discharge was relatively less affected by peripheral movement than the more sustained components. However, these authors did find a compression of the peak discharge as well, but their recordings do not cover a wide enough intensity range to show whether there was an actual depression of the saturation level. 
Acknowledgements - Thanks are due to Drs Simo Hemilä and Tom Reuter for commenting on an earlier version of the manuscript.

\section{REFERENCES}

Bäckström A.-C. and Hemilä S. (1979) Dark-adaptation in frog rods: changes in the stimulus-response function. J. Physiol., Lond. 287, 107-125.

Bäckström A.-C., Hemilä S and Reuter T. (1978) Directional selectivity and colour coding in the frog retina. Med. Biol. 56, 72-83.

Bäckström A.-C. and Reuter T. (1975) Receptive field organization of ganglion cells in the frog retina: contributions from cones, green rods and red rods. $J$. Physiol., Lond. 246, 79-107.

Bäckström A.-C. and Reuter T. (1982) Receptive field organization of ganglion cells in the frog retina: inhibitory surround and direction selectivity. In Receptive fields, sensitivity and directional selectivity of frog ganglion cells and the effects of ethanol and picrotoxin on these properties. Ph.D thesis, Helsingin Yliopiston Monistuspalvelu, Helsinki.

Barlow H. B. (1953) Summation and inhibition in the frog's retina. J. Physiol. Lond. 119, 69-88.

Barlow H. B. (1972) Dark and light adaptation: psychophysics. In Handbook of Sensory Physiology (Edited by Jameson D. and Hurvich L. M.), Vol. VII/4 pp 1-28. Springer, Berlin.

Barlow H. B. (1965) Optic nerve impulses and Weber's law. Cold Spring Harb. Symp. quant. Biol. 30, 539-546.

Barlow H. B. and Levick W. R. (1976) Threshold setting by the surround of cat retinal ganglion cells. J. Physiol., Lond. 259, 737-757.

Baylor D. A., Hodgkin A. L. and Lamb T. D. (1974) The electrical response of turtle cones to flashes and steps of light. J. Physiol., Lond. 242, 685-727.

Baylor D. A., Lamb T. D. and Yau K.-W. (1979) The membrane current of single rod outer segments. $J$. Physiol., Lond. 288, 589-611.

Burkhardt D. A. (1974) Sensitization and centre-surround antagonism in Necturus retina. J. Physiol., Lond. 236, 593-610.

Burkhardt D. A. and Berntson G. G. (1972) Light adaptation and excitation: lateral spread of signals within the frog retina. Vision Res. 12, 1095-1111.

Byzov A. L. and Kusnezova L. P. (1971) On the mechanisms of visual adaptation. Vision Res., Suppl. 3, 51-63.

Copenhagen D. R. (1975) Time course of threshold elevation in on-off ganglion cells of Necturus retina: effects of lateral interactions. Vision Res. 15, 573-581.

Donner K. (1981a) Receptive fields of frog retinal ganglion cells: response formation and light-dark-adaptation J. Physiol., Lond. 319, 131-142.

Donner K. (1981b) How the latencies of excitation and inhibition determine ganglion cell thresholds and response patterns in the frog. Vision Res. 21, 1689-1692.

Donner K. (1987a) Adaptation-related changes in the spatial and temporal summation of frog retinal ganglion cells. Acta physiol. scand. To be published.

Donner K. (1987b) The absolute sensitivity of vision: can a frog become a perfect detector of light-induced and dark rod events? Physica Scripta. To be published.

Donner K. and Grönholm M.-L. (1984) Center and surround excitation in the receptive fields of frog retinal ganglion cells. Vision Res. 24, 1807-1819.

Donner K. and Hemilä S. (1985) Rhodopsin phosphorylation inhibited by adenosine in frog rods: lack of effects on excitation. Comp. Biochem. Physiol. 81A, 431-439.

Donner K., Hydén C. and Reuter T. (1986) Noise and absolute threshold of frog retinal ganglion cells. Acta Univ. Oul. A 179, 35-38.

Donner K. O. and Reuter T. (1968) Visual adaptation of the rhodopsin rods in the frog's retina. J. Physiol., Lond. 199, 59-87.

Enroth-Cugell C. and Jakiela H. G. (1980) Suppression of cat retinal ganglion cell responses by moving patterns. J. Physiol., Lond. 302, 49-72.

Enroth-Cugell C. and Lennie P. (1975) The control of retinal ganglion cell discharge by receptive field surrounds. J. Physiol., Lond. 247, 551-578.

Enroth-Cugell C., Lennie P. and Shapley R. M. (1975) Surround contribution to light-adaptation in cat retinal ganglion cells. J. Physiol., Lond. 247, 579-588.

Gaze R. M. and Jacobson M. (1963) "Convexity" detectors in the frog's visual system. J. Physiol., Lond. 169, 1P-3P.

Grüsser O.-J. and Grüsser-Cornehls U. (1973) Neuronal mechanisms of visual movement perception and some psychophysical and behavioral correlations. In Handbook of Sensory Physiology (Edited by Jung. R.), Vol. VII/3A, pp. 333-429. Springer, Berlin.

Grüsser O.-J., Grüsser-Cornehls U. and Bullock T. H. (1964) Functional organization of receptive fields of movement-detecting neurons in the frog's retina. Pflüger's Arch. ges. Physiol. 279, 88-97.

Hemilä S. O. (1977) Background adaptation in the rods of the frog's retina. J. Physiol., Lond. 265, 721-741.

Lettvin J. Y., Maturana H. R., McCulloch W. S. and Pitts W. H. (1959) What the frog's eye tells the frog's brain. Proc. Inst. Radio. Engrs. 47, 1940-1951.

Marchiafava P. L. (1983) An "antagonistic" surround facilitates central responses by retinal ganglion cells. Vision Res. 23, 1097-1099.

Maturana H. R., Lettvin J. Y., McCulloch W. S. and Pitts W. H. (1960) Anatomy and physiology of vision in the frog (Ranaa pipiens). J. gen. Physiol. 43, 129-175.

Mooney R. D. (1979) GABA and the lateral spread of tonic activity in frog retina. Vision Res. 19, 501-505.

Newman E. A. and Lettvin J. Y. (1978) Relation of the e-wave to ganglion cell activity and rod responses in the frog. Vision Res. 18, 1181-1188.

Normann R. A. and Werblin F. S. (1974) Control of retinal sensitivity. I. Light and dark adaptation of vertebrate rods and cones. J. gen. Physiol. 63, 37-61.

Pickering S. G. and Varjú D. (1967) Ganglion cells in the frog retina: inhibitory receptive field and long-latency response. Nature, Lond. 215, 545-546.

Reuter T., Donner K. and Copenhagen D. R. (1986) Does the random distribution of discrete photoreceptor events limit the sensitivity of the retina? Neurosci. Res., Suppl. 4, S163-S180.

Teller D. Y., Andrews D. P. and Barlow H. B. (1966) Local adaptation in stabilized vision. Vision Res. 6, 701-705.

Thibos L. N. and Werblin F. S. (1978a). The response properties of the steady antagonistic surround in the mudpuppy retina. J. Physiol., Lond. 278, 79-99. 
Thibos L. N. and Werblin F. S. (1978b) The properties of surround antagonism elicited by spinning windmill patterns in the mudpuppy retina. J. Physiol., Lond. 278, 101-116.

Werblin F. S. (1970) Response of retinal cells to moving spots: intracellular recording in Necturus maculosus. $J$. Neurophysiol. 33, 342-350.

Werblin F. S. (1971) Adaptation in a vertebrate retina: intracellular recording in Necturus. J. Neurophysiol. 34, 228-241.

Werblin F. S. (1972) Lateral interactions at the inner plexiform layer of vertebrate retina: antagonistic responses to change. Science, N.Y. 175, 1008-1010.

Werblin F. S. (1974) Control of retinal sensitivity II.
Lateral interactions at the outer plexiform layer. J. gen Physiol. 63, 62-87.

Werblin F. S. and Copenhagen D. R. (1974) Control of retinal sensitivity. III. Lateral interactions at the inner plexiform layer. J. gen. Physiol 63, 88-110.

Werblin F. S. and Dowling J. E. (1969) Organization of the retina of the mudpuppy, Necturus maculosus. II. Intracellular recording. J. Neurophysiol. 32, 339-355.

Westheimer G. (1965) Spatial interaction in the human retina during scotopic vision. J. Physiol. Lond. 181, 881-894.

Westheimer G. (1968) Bleached rhodopsin and retinal interaction. J. Physiol., Lond. 195, 97-106. 